\title{
Medievalista
}

Online

$20 \mid 2016$

Número 20

\section{Jean Favier (1932-2014)}

\section{Armando Luís de Carvalho Homem}

\section{OpenEdition}

\section{Journals}

\section{Edicão electrónica}

URL: http://journals.openedition.org/medievalista/1233

DOI: $10.4000 /$ medievalista.1233

ISSN: 1646-740X

\section{Editora}

Instituto de Estudos Medievais - FCSH-UNL

\section{Refêrencia eletrónica}

Armando Luís de Carvalho Homem, « Jean Favier (1932-2014) », Medievalista [Online], 20 | 2016, posto online no dia 01 dezembro 2016, consultado o 23 setembro 2020. URL : http://

journals.openedition.org/medievalista/1233; DOI : https://doi.org/10.4000/medievalista.1233

\section{(c) (i) (9)}

Mediavalista está licenciado com uma Licença Creative Commons - Atribuição-NãoComercial 4.0 Internacional. 
Título / Title: Jean Favier (1932-2014)

Autor(es) / Author(s): Armando Luís de Carvalho Homem

Universidade / University: Universidade do Porto

Faculdade e Departamento / Unidade de Investigação - Faculty and Department /

Research Center: Faculdade de Letras, Departamento de História e de Estudos Políticos e

Internacionais / Centro de Estudos da População, Economia e Sociedade

Código Postal / Postcode: 4150-564

Cidade / City: Porto

País / Country: Portugal

Email: almisch@gmail.com

Fonte: Medievalista [Em linha]. Direc. Bernardo Vasconcelos e Sousa. Lisboa: IEM.

Disponível em:

http://www2.fcsh.unl.pt/iem/medievalista/MEDIEVALISTA20/homem2011.html

ISSN: 1646-740X

Data de recepção do texto / Received for publication: 29 de Janeiro de 2016 


\section{son}

\section{Jean Favier (1932-2014)}

\section{Armando Luís de Carvalho Homem}

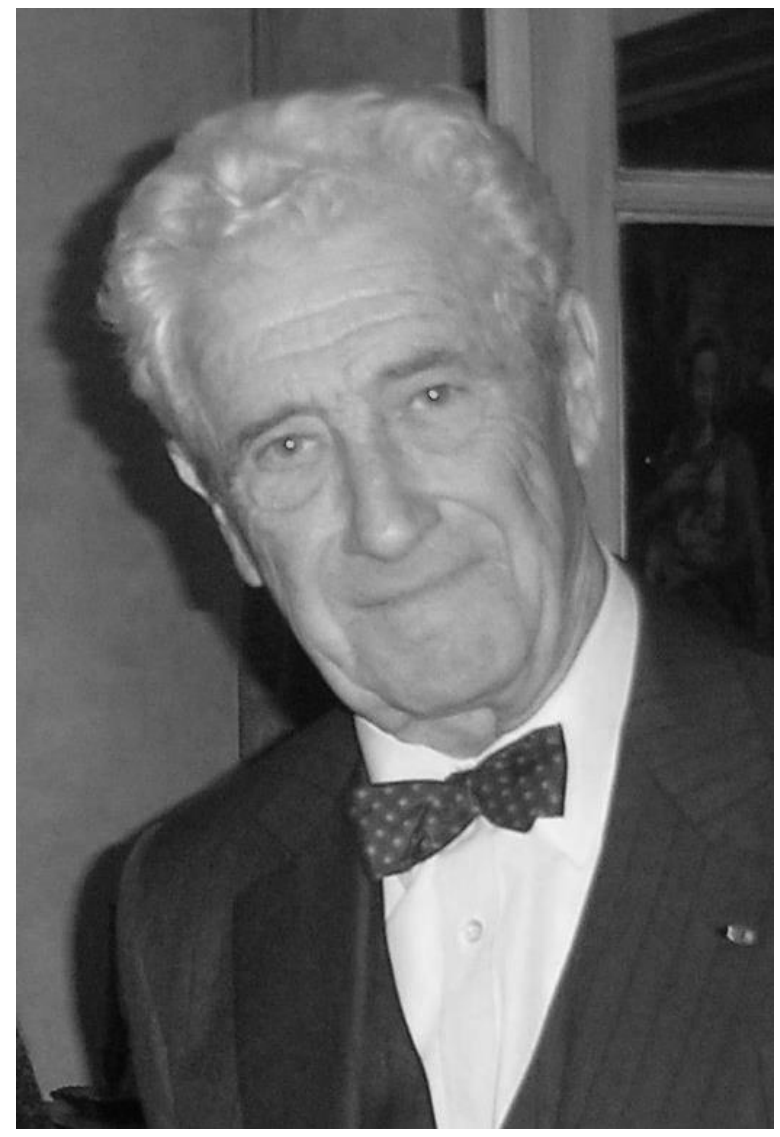

Jean Favier em 2005

Em Agosto de 2014 deixou-nos Jean Favier (JF), membro do Institut de France / Académie des inscriptions et belles-lettres (AIBL) e professor emérito da Universidade de Paris-Sorbonne (Paris IV). Natural de Paris, JF cursou a École des Chartes (1952 ss.), obtendo em 1956 o diploma de archiviste paléographe, após defesa de uma tese sobre Enguerran de Marigny ${ }^{1}$. Nos dois anos subsequentes foi aluno da École Française

\footnotetext{
${ }^{1}$ Nota editorial: As indicações bibliográficas no texto serão remetidas por data para o Apêndice bibliográfico que sucede ao texto, dividido em Bibliografia activa e Bibliografia passiva.
} 
de Rome, ao que se seguiu um período como conservateur aux Archives Nationales. Em 1961 obteve a agrégation d'histoire e no ano lectivo subsequente ensinou no liceu de Orléans. Seguir-se-ão dois anos como attaché de recherches no Centre National de la Recherche Scientifique (CNRS), e em 1964 iniciará o seu percurso propriamente universitário, como maître de conférences nas U's de Rennes (1964-1966) e de Rouen (1966-1969). Em 1965 é eleito Directeur d'études d'histoire administrative et financière du Moyen Âge occidental na École pratique des Hautes Études (IV section: sciences historiques et philologiques), cargo de que será titular até à jubilação (1997).

O ano anterior ao Maio francês assistirá ao seu doctorat d'État em Paris ${ }^{2}$, enquanto que o subsequente verá a sua eleição como professor da então ainda indivisa Sorbonne ${ }^{3}$. No big-bang universitário da viragem da década, será um dos fundadores de Paris IV (Paris-Sorbonne); Favier aqui viria a ensinar até 1975, assumindo o ensino de uma nova cadeira de História Económica ("elle fit mon bonheur") e de Paleografia e presidindo ao Institut d'Histoire a partir de 1970; entre os seus colegas de então menciona especialmente Alphonse Dupront (1905-1990, também fundador e primeiro presidente de Paris IV) e Michel Meslin (1926-2010).

1975 inauguraria entretanto a fase gestionária do percurso de JF: na presidência de Valéry Giscard d'Estaing (1974-1981), e na primeira passagem de Jacques Chirac pela chefia do Executivo (1974-1976), foi nomeado Directeur général des Archives de France, cargo que desempenharia até 1994; neste ano passaria para a presidência da Bibliothèque nationale de France (até 1997); e seria, por último, Presidente da Commision française pour l'Unesco (1997 ss.). Neste interim, ficou "en congé" da sua cadeira em Paris IV, mas manteve até 1997 o ensino da Paleografia, "en bonne partie par fidélité à la mémoire de mon maître Alain de Boüard, à qui je devais d'avoir compris que le document parle à l'historien et qu'il faut apprendre aux jeunes à dialoguer avec les textes"4.

Publ.: FAVIER, 1963.

${ }^{2}$ Tese principal. FAVIER, 1966a; Directeur de thèse: Michel Mollat du Jourdin (1911-1996).

${ }^{3}$ Foi o último escolhido para professor "de l'ancienne Sorbonne entière" (FAVIER - "Cheminements", in Apêndice bibliográfico: Bibliografia passiva, 1999 (p. 12).

${ }^{4}$ FAVIER - "Cheminements", in Apêndice bibliográfico: Bibliografia passiva, 1999 (p. 12). 
Foi ainda membro do Institut / AIBL (1985 ss., presidente da AIBL em 1995) ${ }^{5}$; director da Revue Historique (1973-1997); vice-presidente (1984-1988) e presidente (19881992) do Conseil international des archives; presidente do Conseil d'administration da École normale supérieure (1989-1997); membro residente (e presidente, 1993) da Société nationale des antiquaires de France; membro do Comité des travaux historiques et scientifiques; membro do conselho executivo do Instituto Francesco Datini (Prato); e conservador do château de Langeais (1995-2012) ${ }^{6}$.

Internacionalmente, pertenceu à Commission Internationale de Diplomatique (CID), à Mediaeval Academy of America, à Académie royale des Sciences, des Lettres et des Beaux-Arts de Belgique, ao Institut Grand-Ducal (Luxemburgo) e à Society of Antiquaries of London; e recebeu o doutoramento h.c. pelo Instituto de Paleografia e Diplomática da U. de Roma.

Que balanço para uma obra extensa e polimorfa?

$\mathrm{Na}$ École des Chartes e na formação post-graduada, JF teve mestres (lato sensu) como Robert Fawtier (1885-1966), Alain de Boüard (1882-1955), Clovis Brunel (1884-1971), André Piganiol (1883-1968), Pierre Renouvin (1893-1974), Yves Renouard (19081965), Robert Boutruche (1904-1975) e Michel Mollat. De todos reteve algo. Por outro lado, nos seminários de Boutruche e Mollat que frequentou em Paris nas décadas de 50 e de 60, cruzou-se com Guy Fourquin (1925-1988), Bernard Guenée (1927-2010), Pierre Toubert, Philippe Contamine, Charles de la Roncière, Bronislaw Geremek (19322008), André Vauchez, Henri Dubois (1923-2012) e Jacques Le Goff (1924-2014).

Tais mestres e colegas, bem como a conjuntura historiográfica de meados da década de 50, atraíram-no, ao projectar a tese final do período chartiste, para a época de Filipe IV, o Belo e para a problemática dos seus homens de leis. Depois de pensar nas figuras de Guillaume de Nogaret e de Guillaume de Plaisians, aconselhou-se com Charles-Edmond Perrin (1887-1974) e depois com R. Fawtier, assentando em Enguerran de Marigny. A

\footnotetext{
${ }^{5}$ A AIBL atribuiu-lhe, aliás, dois $2 .^{\text {os }}$ e um $1 .^{\circ}$ Prix Gobert (1964, 1965 e 1968, respectivamente).

${ }^{6}$ Património do Institut.
} 
esta personagem dedicou a tese (ainda hoje de bem profícua consulta) e uma edição de fontes ${ }^{7}$; e deixou-nos um sólido "dossier" historiográfico sobre os "légistes" philippinos ${ }^{8}$.

O tempo passado na École Française de Rome levou-o a conceber como tese doutoral a apresentar à Sorbonne um extenso projecto sobre as finanças pontificais ao tempo do Grande Cisma ${ }^{9}$. O orientador seria Yves Renouard; mas a morte prematura deste em 1965 levou à indigitação de Michel Mollat ${ }^{10}$; prestou provas em 1967, como se disse.

JF virá a salientar que diversos desenvolvimentos da sua obra derivarão da formação diplomatística (e do seu ulterior ensino nesta área) e do interesse precoce pela História dos poderes, pela edição ou problematização das fontes, pela abordagem biográfica ${ }^{11}$, pela História administrativa, financeira e fiscal ${ }^{12}$, bem como por algumas grandes sínteses ${ }^{13}$ ou pelo produtivo interesse pela História de Paris ${ }^{14}$; enquanto que, ainda que com raízes já na pesquisa doutoral, o seu ensino de História económica frutificará em alguns outros volumes de largo fôlego, sobre ouro, especiarias ou comércio fluvial ${ }^{15}$.

No fundo, JF realizou as sínteses possíveis da sua formação, do seu percurso universitário, do seu ensino e do seu desempenho consecutivo de cargos académicos, de gestão científica ou de altas Funções Públicas (normalmente designado por Executivos da família gaullista) ao longo de mais de três décadas. Alguém a ser recordado mais pela carreira do que pela obra, como ouvi comentar em Paris no final dos anos 90? Parece-me excessivo; malgré tout... Alguém, afinal, que eu também teria gostado de conhecer... ${ }^{16}$

\footnotetext{
${ }^{7}$ FAVIER, 1963 e 1965.

${ }^{8}$ FAVIER, 1969.

${ }^{9}$ FAVIER, 1966a.

${ }^{10}$ V. supra, n. ${ }^{2}$.

${ }^{11}$ Prosseguida em FAVIER, 1978, 1982, 1999, 2001 e 2010.

${ }^{12}$ FAVIER, 1963, 1965, 1968b, 1970, 1971 (obras nascida de um ciclo de lições proferidas a convite de J. Le Goff), 1975b, 1988b, 1990,

${ }^{13}$ FAVIER, 1968a, 1980, 1983a (Dir.), 1993a (Dir.), 1996 (Dir.), 1997b, 2004 e 2006.

${ }^{14}$ FAVIER, 1973, 1974, 1997b e 2012.

${ }^{15}$ FAVIER, 1975a e 1987.

${ }^{16}$ Como já foi dito, Jean Favier pertenceu à CID, organismo para o qual eu próprio fui eleito em 1990; mas não tive oportunidade de o encontrar nos Colóquios do organismo em que participei (Sevilha, Porto / Braga / Coimbra, Montréal, Gand e Bolonha).
} 
Resta dizer que JF foi também um homem de família; um apreciador de fotografia e de jardinagem; e ainda um melómano ${ }^{17}$, ele próprio executante de violino na infância e de órgão ${ }^{18}$ e cravo na idade madura ${ }^{19}$; ou seja, pessoa de certa forma com gostos requintados, do que o uso sistemático de laço ("noeud papillon") quando em "toilette" formal também pode ser um bom indício ${ }^{20} \ldots$

Foi casado (1956 ss.) com Lucie Favier ("née Calisti", 1932-2003), sua colega de curso na École des Chartes e depois também archiviste paléographe, com exercício profissional nos Archives Nationales (1959-1988) e termo de carreira como inspecteur général des archives de France (1988-1998).

\section{A fechar (um episódio "sui generis", narrado pelo próprio):}

"J'ai donc enseigné dans le sécondaire. (...) Pour enseigner le Moyen Âge au lycée, il fallait avoir raté l'agrégation. On me l'a proprement dit: "La quatrième, ce n'est pas pour les agrégés". J'ai pensé que ma place était ailleurs, mais je suis parti avec le sentiment que cette année de lycée m'avait beaucoup appris.

L'inspecteur général qui vice-présidait le jury d'agrégation, et qui était paternel, nous avait conseillé de ne pas porter de noeud papillon, à peine d'être chahuté. Je retins la moitié de la leçon: il y avait un risque. J'abordai donc mes élèves en leur disant: "Si vous vous tenez bien, je vous promets qu'à la fin de l'année je vous apprendrai à nouer un noeud". Je n'avais pas eu de difficultés avec mes élèves et j'avais oublié mon propos quand, le dernier jour, je m'entendis rappeler: "M'sieu z'aviez fait une promesse...". J'espère bien que mes anciens éléves ont retenu l'art de nouer un noeud"21.

\footnotetext{
${ }^{17}$ Presidiu nos anos 90 à Nouvelle Académie du disque.

${ }^{18}$ Veja-se, a propósito, FAVIER, 1992.

19 "Au soir d'une journée difficile, rien ne vaut une page de Bach ou de Couperin pour vous remettre les neurones en forme" (FAVIER - "Cheminements", in Apêndice bibliográfico: Bibliografia passiva, 1999, p. 15). Foi, aliás, membro dos júris dos concursos internacionais de órgão de Chartres (1996) e de Paris (1997).

${ }^{20} \mathrm{Cf}$. infra, episódio narrado a encerrar.

${ }^{21}$ FAVIER - "Cheminements", in Apêndice bibliográfico: Bibliografia passiva, 1999 (p. 12).
} 


\section{Apêndice bibliográfico}

\section{Bibliografia activa (selecção)}

1959: Archives (Les). Paris: PUF (coll. "Que sais-je?". N. 805; reeds. até 1997; trads. em jap. e em chin.).

1963: Un conseiller de Philippe le Bel, Enguerran de Marigny. Paris: PUF (tese / École des Chartes).

1965: Cartulaire et actes d'Enguerran de Marigny. Paris: Imprimerie Nationale.

1966a: Finances (Les) pontificales à l'époque du Grand Schisme d'Occident, 13781409. Paris: De Boccard (tese principal de doctorat d'État, Sorbonne).

1966b: "Histoire d'un déficit: les finances de Charles VI". Bibliothéque de l'École des Chartes, pp. 514-525.

1968a: De Marco Polo à Christophe Colomb, 1250-1492. Paris: Larousse.

1968b: "Histoire (L') administrative et financière du Moyen Âge depuis dix ans". Bibliothéque de l'École des Chartes, pp. 514-525.

1969: "Légistes (Les) et le gouvernement de Philippe le Bel". Journal des Savants, pp. 92-108.

1970: Contribuables (Les) parisiens à la fin de la Guerre de Cent ans. Paris / Genebra: Droz.

1971: Finance et fiscalité au bas Moyen Âge. Paris: SEDES.

1973: "Une ville entre deux vocations, la place d'affaires de Paris au XV siècle". Annales ESC, pp. 1245-1279.

1974: Paris au XVe siècle, 1380-1500. Paris: Diff. Hachette (reed. em 1997).

1975a: Commerce (Le) fluvial dans la région parisienne au XVe siècle, le registre des compagnies françaises, 1449-1467. Paris: Imprimerie municipale.

1975b: "Entourage (L') politique du prince au Moyen Âge". in Origines et histoire des cabinets des ministres en France. Paris: EPHE / IV ${ }^{\mathrm{e}}$ section, pp. 5-10.

1978: Philippe le Bel. Paris: Fayard (trad. em it.).

1980: Guerre (La) de Cent Ans. Paris: Fayard.

1982: François Villon. Paris: Fayard (trads. em russo e em esp.).

1983a (Dir.): France (La) médiévale. Paris: Fayard.

1983b: "Charles Samaran", Bibliothèque de l'École des Chartes, pp. 410-426.

1984: Temps (Le) des principautés. Paris: Fayard (trad. em al.). 
1984-1987 (Dir.): Histoire de France, 6 vols.

1987: De l'or et des épices. Naissance de l'homme d'affaires au Moyen Âge. Paris: Fayard (trads. em it., em neerl. e em chin.).

1988a, em col. com FAVIER, Lucie: Archives nationales, quinze siècles d'histoire. Paris: Fernand Nathan.

1988b: "Transmission (La) de la couronne: les sources d'une légitimité", in Institut de France, séance publique annuelle, Paris, pp. 1-13.

1990: "Traits généraux et traits spécifiques de l'administration pontificale", in Aux origines de l'État moderne, le fonctionnement administratif de la papauté d'Avignon. Roma: École française de Rome, pp. 1-4.

1992: "Autour de l'orgue", in Orgues (Les) de Paris. Paris: Délégation à l'action artistique de la Ville de Paris, pp. 27-35.

1993a: Dictionnaire de la France médiévale. Paris: Fayard.

1993b (Dir.): Pratique (La) archivistique française. Paris: Fayard.

1994: "Des arts libéraux à la pluridisciplinarité, approches de l'encyclopédisme", in Académie des inscriptions et belles-lettres, séance publique annuelle, célébration du bicentenaire de l'École normale supérieure, pp. 19-31.

1995a: "Quand l'érudition s'appuie sur les techniques", in Institut de France, séance publique annuelle des cinq académies. Découvertes et événements culturels remarquables du dernier siècle. Paris, pp. 13-20.

1995b: "Discours du Président", in Institut de France, Académie des Inscriptions et Belles-Lettres, Paris, pp. 3-10.

1995c: "Pour un savoir convivial", in Apprentissage $\left(L^{\prime}\right)$ du savoir vivant, fonction des grands collèges européens, bicentenaire de la fondation de l'École normale supérieure, Paris, pp. 231-235.

1995d, em col. c/ NEIRINCK, Danièle: "Archives (Les)", in BÉDARIDA, François (Ed.) - Histoire $\left(L^{\prime}\right)$ et le métier d'historien en France, 1945-1995. Paris: Maison des sciences de l'homme, pp. 89-110.

1996 (Dir.:): XIVe et XVe siècles: crises et genèses. Paris: PUF.

1997a: "Devenir chartiste ", in Cole (L') national des chartes. L'histoire de l'École depuis 1821. Paris: pp. 161-165.

1997b: Paris, deux mille ans d'histoire. Paris: Fayard.

1999: Charlemagne. Paris: Fayard. 
2001: Louis XI. Paris: Fayard.

2004: Plantagenêts (Les): origines et destin d'un empire, XI ${ }^{e}$-XIV $V^{e}$ siècles. Paris: Fayard. 2006: Papes (Les) d'Avignon. Paris: Fayard.

2010: Pierre Cauchon ou les maîtres dans la tourmente. Paris: Fayard.

2012: Bourgeois (Les) de Paris au Moyen Âge. Paris: Tallandier.

\section{Bibliografia passiva}

1999: KERHEVÉ, Jean; RIGAUDIÈRE, Albert (Dir.) - Finances, pouvoirs et mémoire. Mélanges offerts à Jean Favier. Paris: Fayard; cf., pp. 7-16: FAVIER, J. "Cheminements au long d'une vie"; e, pp. 17-23, um currículo sumário e uma Bibliografia activa.

2014a: In Memoriam, sur le site de l'Académie des inscriptions et belles-lettres [Em linha]. [Consultado em 22 Jan. 2016]. Disponível em http://www.aibl.fr/membres/inmemoriam/article/2014-1212?lang=fr

2014b: Académiciens depuis 1663, sur le site officiel de l'Académie des inscriptions et belles-lettres [Em linha]. [Consultado em 22 Jan. 2016]. Disponível em http://www.aibl.fr/membres/academiciens-depuis-1663/article/favier-jean?lang=fr

\section{COMO CITAR ESTE ARTIGO}

\section{Referência electrónica:}

CARVALHO HOMEM, Armando Luís de - "Jean Favier (1932-2014)".

Medievalista [Em linha]. N. 20 (Julho - Dezembro 2016). [Consultado dd.mm.aaaa].

Disponível em

http://www2.fcsh.unl.pt/iem/medievalista/MEDIEVALISTA20/homem2011.html ISSN 1646-740X. 


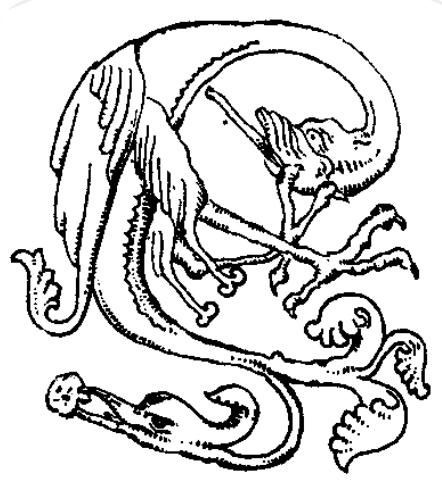

